\title{
Spinal Interneurons That Are Selectively Activated during Fictive Flexion Reflex
}

\author{
Ari Berkowitz \\ Department of Zoology, University of Oklahoma, Norman, Oklahoma 73019
}

\begin{abstract}
Behavioral choices in invertebrates are mediated by a combination of shared and specialized circuitry, including neurons that are inhibited during competing behaviors. Less is known, however, about the neural mechanisms of behavioral choice in vertebrates. The spinal cord can appropriately select among several types of limb movements, including limb withdrawal (flexion reflex), scratching, and locomotion, and thus is conducive to examination of vertebrate mechanisms of behavioral choice. Flexion reflex can interrupt and reset the rhythm of scratching and locomotion, suggesting that a combination of shared and specialized circuitry contributes to these behaviors, but little is known about the interneurons involved. Here, I used in vivo intracellular recording and dye injection to identify a group of spinal interneurons that are strongly activated during fictive flexion reflex but inhibited during fictive scratching and fictive swimming. These flexion-selective interneurons are typically rhythmically hyperpolarized during fictive scratching and fictive swimming. This hyperpolarization can be maximal during the ipsilateral hip flexor bursts of rhythmic limb motor patterns, although these cells are strongly activated during the ipsilateral hip flexor bursts of fictive flexion reflex. Thus, these interneurons are relatively specialized for fictive limb withdrawal, rather than contributing to the hip flexor phase of multiple types of limb movements. These flexion-selective cells are physiologically and morphologically distinguishable from a recently described group of spinal interneurons (transverse interneurons) that are strongly activated during both fictive flexion reflex and fictive scratching. Thus, spinal interneurons with distinct behavioral roles may to some extent be morphologically distinguishable.
\end{abstract}

Key words: flexion; withdrawal; scratch; locomotor activity; interneurons; spinal cord; central pattern generator; dorsal horn

\section{Introduction}

Nervous systems must make appropriate, fast, and reliable behavioral choices. Cellular mechanisms of behavioral choice are best understood for several invertebrate systems, in which many CNS neurons contribute to multiple behaviors, whereas others are dedicated to just one (Morton and Chiel, 1994; Marder and Calabrese, 1996; Kristan and Shaw, 1997; Edwards et al., 1999; Kupfermann and Weiss, 2001; Jing et al., 2004; Briggman et al., 2005; Marder et al., 2005; Briggman and Kristan, 2006). In some cases, CNS neurons dedicated to one behavior inhibit CNS neurons dedicated to another behavior.

Less is known about cellular mechanisms underlying behavioral choices in vertebrates (Marder, 2000; Berkowitz, 2005). The brain contributes critically to deliberative choices in primates (Schall, 2001; Platt, 2002; Sugrue et al., 2005). Rapid choices among fundamental behaviors, such as locomotion, scratching, and limb withdrawal, however, can be made by spinal networks in the absence of brain inputs and movement-related sensory feedback (Stein, 2005). Spinally mediated behaviors are especially

Received Dec. 25, 2006; revised March 20, 2007; accepted March 21, 2007.

This work was supported by National Science Foundation Grants 9807991 and 0349620. I thank R. Mark Ballard for assistance with surgical dissections, Gina L. C. Yosten for assistance with morphological reconstructions, and Dr. Paul S. G. Stein for comments on a previous version of this manuscript.

Correspondence should be addressed to Ari Berkowitz, Department of Zoology, University of Oklahoma, 730 Van Vleet Oval, Norman, OK 73019. E-mail: ari@ou.edu.

DOI:10.1523/JNEUROSCI.5602-06.2007

Copyright $\odot 2007$ Society for Neuroscience $\quad$ 0270-6474/07/274634-08\$15.00/0 conducive to investigation of cellular mechanisms. It is now known, for example, that many, but not all, of the spinal premotor interneurons that contribute to fictive struggling also contribute to fictive swimming in embryonic tadpoles (Soffe, 1993). Similarly, many but not all of the spinal interneurons that contribute to fictive scratching are also activated during fictive swimming in turtles (Berkowitz, 2002, 2005).

Limb withdrawal from a tactile stimulus, or flexion reflex, has been studied for more than a century and has been a focus of work on spinal cord nociception and plasticity (Sherrington, 1906, 1910; Schouenborg, 2002; Sandrini et al., 2005). It can be evoked by noxious or innocuous cutaneous or deep stimulation and involves contraction of several flexor muscles, along with relaxation of several extensor muscles. Sherrington recognized similarities between flexion reflex and the flexion phases of scratching and stepping but noted that flexion reflex can interrupt scratching or stepping, and vice versa; he thus suggested that flexion reflex stimuli compete with scratch and step stimuli to control muscles (Sherrington, 1906, 1910). It was later suggested, however, that a common "flexor reflex afferents" network contributes to limb withdrawal, locomotion, and scratching (Jankowska et al., 1967; Lundberg, 1979). Moreover, flexion reflex can reset an ongoing scratch or locomotor rhythm, indicating that some flexion reflex circuitry may be shared with rhythmgenerating circuitry (Currie and Stein, 1989; Schomburg et al., 1998).

These studies suggest that spinal networks for withdrawal and 


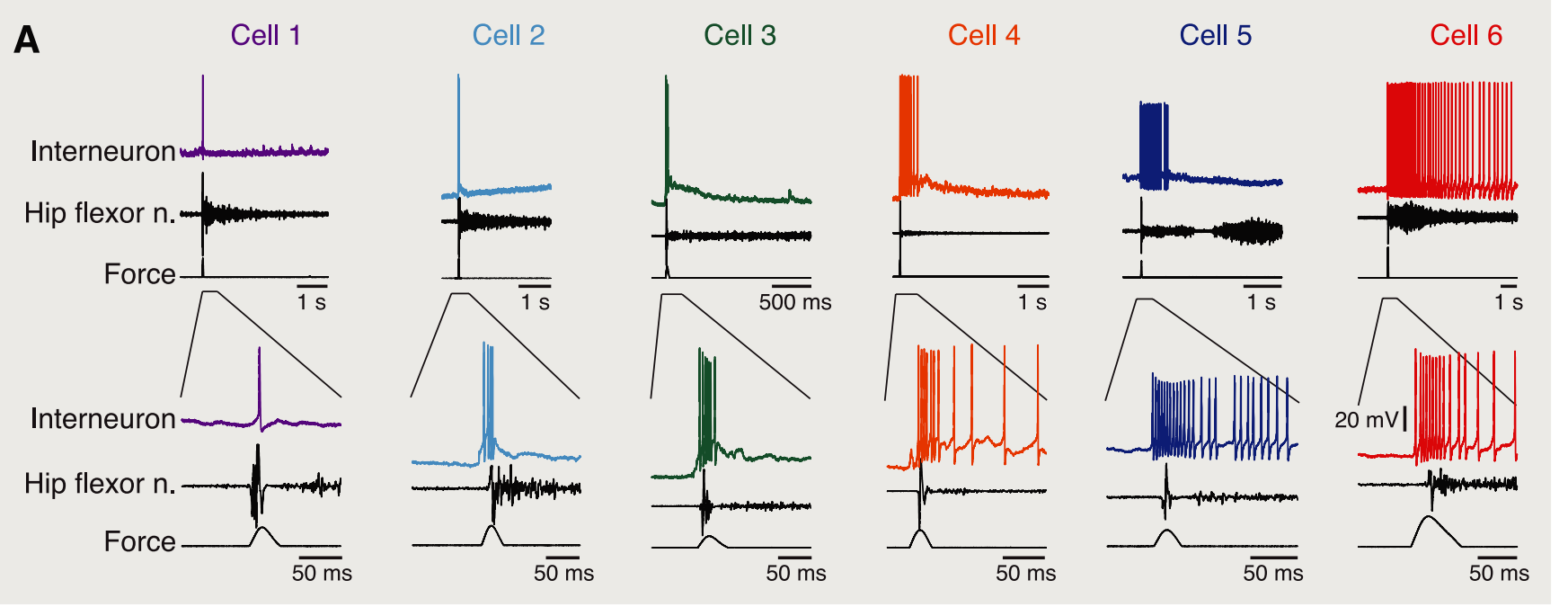

B

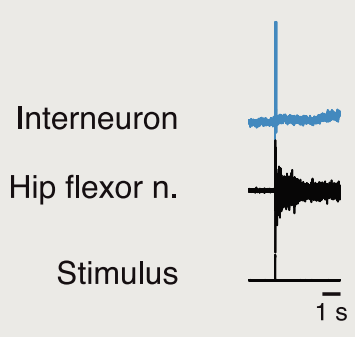

Cell 2, expanded

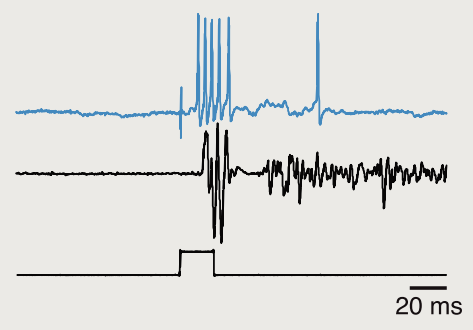

Cell 4

Cell 4, expanded

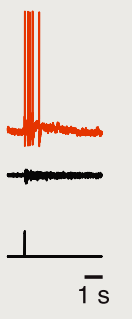

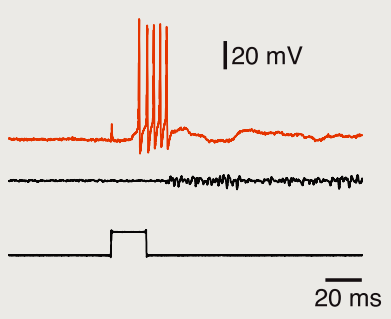

Figure 1. Flexion-selective interneuron responses during ipsilateral fictive flexion reflex. $A$, Examples of six flexion cells during foot tap-evoked fictive flexion reflex. The bottom sets of traces expand the early portions of the responses. $\boldsymbol{B}$, Flexion cell responses to electrically evoked fictive flexion reflex for two of the cells shown in $\boldsymbol{A}$. Note that flexion cell responses can begin within $20 \mathrm{~ms}$ of stimulus onset, before the ipsilateral hip flexor nerve burst. In this and subsequent figures, voltage scale bars apply to all cells in that figure panel. n., Nerve.

rhythmic limb movements include both shared and specialized components. Little is known, however, about the interneurons involved. The turtle is ideal for such investigations, because several types of spinally generated hindlimb motor patterns have been analyzed (Stein, 2005). We recently found that many spinal interneurons are activated during both fictive withdrawal and fictive scratching, including a morphological and physiological subset we call transverse interneurons (Berkowitz et al., 2006). I now report that a separate set of interneurons is strongly activated during fictive withdrawal but either not activated or inhibited during fictive scratching and fictive swimming. Some results were reported previously in an abstract (Berkowitz, 2006).

\section{Materials and Methods}

Physiological and histological methods have been described previously (Berkowitz, 2005) and are briefly summarized here.

Animal preparation. In anesthetized adult red-eared turtles (Trachemys scripta elegans; $400-1000 \mathrm{~g} ; n=12$ ), the spinal cord was transected between the dorsal 2 (D2) and D3 dorsal roots, the spinal cord was exposed from the D6 through the sacral 2 (S2) segments, and several hindlimb motor nerves were exposed and dissected free for electroneurographic recording (Robertson et al., 1985; Berkowitz, 2001). The animal was then immobilized with gallamine $(8 \mathrm{mg} / \mathrm{kg}, \mathrm{i} . \mathrm{m}$.) and artificially respirated at room temperature. All animal procedures were approved by the Institutional Animal Care and Use Committee of the University of Oklahoma.

Electrophysiology. Intracellular recordings were obtained from the gray matter on the right side of the hindlimb enlargement (segments D8, D9, D10, S1, and S2) spinal cord, using sharp microelectrodes filled with $4 \%$ Neurobiotin (Vector Laboratories, Burlingame, CA). Fictive flexion re- flex was elicited by a light tap to the dorsum of the foot using a smooth glass probe attached to a force transducer (Grass/Astro-Med, West Warwick, RI) or via current passage between a pair of gold-plated disk electrodes (Grass/Astro-Med) coated with electrode cream and in contact with skin of the dorsal foot (Currie and Stein, 1989). Fictive hindlimb scratching was elicited by gentle rubbing of the shell or skin with the glass probe. Fictive swimming was evoked using a pair of $100 \mu \mathrm{m}$ silver wires to deliver a $40 \mathrm{~Hz}$ train of bipolar electrical stimuli to the left D3 lateral funiculus (Lennard and Stein, 1977; Juranek and Currie, 2000; Berkowitz, 2002). All signals were stored using a digital audio tape recorder (TEAC America, Montebello, CA) and analyzed off-line using Datapac 2000 software (Run Technologies, Laguna Hills, CA).

Neurobiotin injection and histology. After physiological characterization of each cell, $+0.5-3.8 \mathrm{nA}$ sinusoidal current was injected for 1-30 min to eject Neurobiotin. No more than one interneuron fill was attempted in each spinal cord segment, to ensure unambiguous identification. The animal was then anesthetized with pentobarbital and transcardially perfused with saline, followed by $4 \%$ chilled paraformaldehyde. The D8-S2 spinal cord was postfixed, cryoprotected, embedded, and frozen sectioned at $100 \mu \mathrm{m}$ horizontally. Cell labeling was revealed via incubation with $\mathrm{ABC}$ and $\mathrm{SG}$ reagents (Vector Laboratories); sections were counterstained with nuclear fast red (Vector Laboratories).

Morphological analysis. All successfully filled interneurons that were activated during ipsilateral fictive flexion reflex but not ipsilateral fictive scratching were included in this study. Reconstructions were made via a camera lucida. Rostrocaudal and mediolateral dendritic lengths were measured from reconstructions; dorsoventral dendritic lengths were estimated from the number of horizontal sections containing portions of the dendrites. Processes that could not be unambiguously determined to be axonal were assumed to be dendritic (Berkowitz, 2005). Soma mean diameter was calculated as the average of the major and minor axis di- 
ameters in horizontal sections. All soma measurements were made from high-magnification camera lucida tracings of the somata alone.

Physiological analysis. To calculate dualreferent phase-averaged membrane potential oscillations, any action potentials were deleted from the intracellular recording (and the missing voltage values were interpolated from the values just before and after the action potential), the recording was then linearly smoothed with a time constant of $200 \mathrm{~ms}$, and the signal was dual-referent phase normalized (with respect to rectified and smoothed bursts and interburst intervals of the ipsilateral hip flexor nerve) and averaged for all cycles of that form of fictive scratching or swimming, using Datapac 2000 (Berkowitz and Stein, 1994; Berkowitz, 2005). The form of ipsilateral scratching with the largest phase-averaged oscillation for each cell was used for averages across cells. In some cases, phase-averaged oscillations during contralateral fictive scratching were also calculated, with respect to the contralateral hip flexor nerve.

\section{Results}

\section{Physiology}

Each interneuron included in this study $(n=12)$ was activated during ipsilateral fictive flexion reflex (Fig. 1) but not during ipsilateral fictive scratching. During a tap to the dorsal foot, these flexion reflexselective cells (hereafter termed "flexion cells") usually fired a series of action potentials, beginning before ipsilateral hip flexor nerve activity (Fig. $1 A$, cells 2-6), although some had a longer latency or fired only one action potential (Fig. $1 \mathrm{~A}$, cell 1). To obtain a more precise measure of latency, in some cases fictive flexion reflex was elicited via electrical stimulation of the dorsal foot skin; in these cases, flexion cell discharge could begin within $20 \mathrm{~ms}$ of stimulus onset, before the onset of hip flexor nerve discharge (Fig. $1 B$ ).

During ipsilateral fictive scratching, each flexion cell either showed no clear response (Fig. 2, cells 1,3) or was inhibited (Fig. 2 , cells 2, 4-6). Cells with spontaneous activity had their firing reduced or eliminated during fictive scratching (Fig. 2, cells 5, 6). Some cells without spontaneous activity fired soon after fictive scratching ended, perhaps because of postinhibitory rebound (Fig. 2, cells 1,2); in some cases, a cell fired action potentials at stimulus onset but was then silent during the scratch rhythm itself (Fig. 2, cell 4, pocket and caudal scratching). Many cells were hyperpolarized during fictive scratching, and this hyperpolarization generally included a rhythmic component (Fig. 2, cells 2, 4-6). Cells hyperpolarized during one form of ipsilateral fictive scratching were typically hyperpolarized during all three forms of ipsilateral fictive scratching (Fig. 2, cell 4).

To examine the rhythmic modulation of cells' membrane potentials in more detail, dual-referent phase-averaged membrane potentials were calculated with respect to the hip flexor nerve activity cycle of ipsilateral fictive scratching (Fig. 3). Some cells showed strong scratch phase-locked rhythmic modulation with a single peak and a single trough (Fig. 3, cells 4,5), whereas other cells showed weaker modulation with a more complex waveform
(Fig. 3, cells 1,6). The maximal hyperpolarization (i.e., the trough of the membrane potential oscillation) could occur at a variety of phases of the ipsilateral hip flexor nerve activity cycle (Fig. 3, arrows; see Fig. 5A). Surprisingly, in seven of the 12 cells, the maximal hyperpolarization occurred during the ipsilateral hip flexor bursts. That is, during fictive flexion reflex, all of these cells were depolarized and fired action potentials during the hip flexor burst. However, during fictive scratching, seven of these cells were maximally hyperpolarized during the hip flexor bursts (Fig. 3, cells 4-6; see Fig. 5A).

In some cases, cells were also studied during other fictive motor patterns (Fig. 4). All flexion cells that were hyperpolarized during ipsilateral fictive scratching and were recorded during ipsilateral fictive forward swimming were also hyperpolarized during fictive swimming $(n=4)$ (Fig. $4 A$ ). Hyperpolarization during fictive swimming could also include a rhythmic component, and the maximal hyperpolarization could occur during the ipsilateral hip flexor bursts of fictive swimming (Fig. 4A, B). During fictive flexion reflex of the contralateral hindlimb, some flexion cells were hyperpolarized (Fig. 4C, cells 1, 4), whereas others were depolarized (Fig. $4 C$, cell 5) or were sequentially hyperpolarized and depolarized (Fig. 4C, cell 3). During contralateral fictive scratching, some cells were rhythmically hyperpolarized (Fig. 4D), whereas others showed no clear response (data not shown).

Phase-averaged membrane potentials of flexion cells can be 

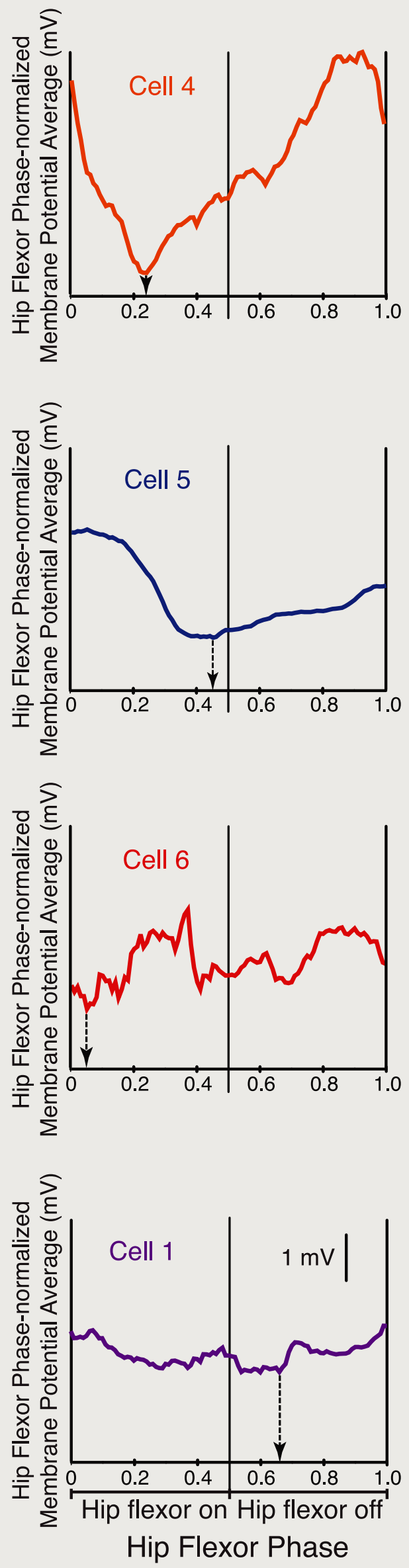

compared with those previously described for scratch-activated spinal interneurons (Berkowitz et al., 2006). The mean amplitude (trough-to-peak) of membrane potential oscillations in flexion cells during ipsilateral fictive scratching $(n=12)$ was significantly less than that of scratch-activated interneurons as a single group $(n=45)$ during ipsilateral fictive scratching ( $p=0.003$; MannWhitney Test). In addition, the mean scratch oscillation amplitude of flexion cells was significantly less than that of transverse interneurons ("T neurons") $(n=16)$, a morphological subset of scratch-activated interneurons $(p=0.0006)$ (Fig. $5 B)$; the difference between the scratch oscillation amplitude in flexion cells and non-T neurons $(n=14)$ was not quite significant ( $p=$ 0.056 ) (Fig. 5B). Only four flexion cells were studied during fictive swimming, and the differences between the mean swim oscillation amplitude in flexion cells and the mean scratch oscillation amplitudes in scratch-activated interneurons, treated either as a single group or as two subgroups, were not significant $(p>$ 0.1 ) (Fig. 5B).

\section{Morphology}

Flexion cells were morphologically heterogeneous, yet they displayed several morphological features that distinguish them from scratch-activated cells generally and from $\mathrm{T}$ neurons in particular (Berkowitz et al., 2006). Flexion cells often had dendritic trees that were at least as extensive rostrocaudally as in the transverse plane (Fig. 6), unlike T neurons. Flexion cell dendrites typically ramified mostly or entirely within the ipsilateral dorsal horn, unlike most scratch-activated interneurons generally. Soma diameter of flexion cells varied substantially (mean \pm SEM, $22.5 \pm$ $3.2 \mu \mathrm{m}$ ). Soma shape of flexion cells also varied substantially but in some cases showed rostrocaudal elongation (Fig. 6), unlike T neurons. A subset of flexion cells had "bushy" processes with extensive higher-order branching and swellings at the ends of fine terminal branches (Fig. 6B); whether these swellings were dendritic spines or axonal boutons could not be determined with certainty. Ratios of dendritic lengths [rostrocaudal/(mediolateral + dorsoventral)] and somatic lengths (rostrocaudal/mediolateral) were variable for flexion cells and overlapped with those of scratch-activated interneurons generally, but were distinct from those of T neurons (Fig. 7A). One flexion cell met the quantitative T neuron criteria (Fig. $7 A$, purple) but only because this cell had a process (which may or may not be dendritic) that arborized in the contralateral gray matter, greatly increasing its mediolateral dendritic length (Fig. $6 \mathrm{~B}$, cell 1). In contrast, no T neurons have been found to have a contralateral dendrite (Berkowitz et al., 2006).

All flexion cells had their soma in the dorsal horn, in contrast to scratch-activated interneurons generally and to $\mathrm{T}$ neurons in particular (Fig. 7B). The three flexion cells with bushy processes (Fig. $6 \mathrm{~B}$ ) each had their soma in the dorsomedial portion of the dorsal horn (Fig. 7B, brown, purple, light green). Flexion cell somata were found in all five segments of the hindlimb enlargement (D8, two; D9, one; D10, four; S1, four; S2, one).

Five flexion cells had a visible funicular axon: the axon of cell 3 crossed and ascended within the contralateral ventral funiculus;

Figure 3. Dual-referent phase-averaged membrane potentials with respect to the ipsilateral hip flexor nerve bursts and interburst intervals during ipsilateral fictive scratching, for four of the cells shown in Figures 1 and 2. Arrows indicate the phase of maximal hyperpolarization in each cell, which could occur during the ipsilateral hip flexor bursts. Cycle periods of all analyzed cycles were $3.17 \pm 0.69 \mathrm{~s}$ (mean \pm SD) for ipsilateral rostral scratching, $2.44 \pm 0.99 \mathrm{~s}$ for ipsilateral pocket scratching, and $3.54 \pm 1.50$ s for ipsilateral caudal scratching. 
the axon of cell 5 bifurcated, ascending and descending in the ipsilateral ventral funiculus; the axon of a third cell ascended in the ipsilateral dorsal funiculus; the axon of a fourth cell bifurcated, ascending and descending within the ipsilateral dorsal funiculus; and the axon of a fifth cell descended within the ipsilateral dorsal funiculus. Thus, flexion-selective cells were heterogeneous with respect to their axonal projections and likely synaptic targets. Unambiguous axon-terminal arborizations were found for three cells: cell 5 had axon terminals in the ipsilateral intermediate zone and ventral horn; a second cell had axon terminals in the ipsilateral dorsal horn and intermediate zone; and a third cell had axon terminals in the ipsilateral dorsal horn.

\section{Discussion}

Flexion cells are selectively activated during fictive withdrawal

This study demonstrates that there are spinal interneurons that are selectively activated during fictive hindlimb withdrawal (flexion reflex). The dorsal horn soma locations and short latencies of these flexion cells suggest that they may function as sensory interneurons for flexion reflex. These cells may be part of the flexion reflex pathway that is selectively affected by an NMDA antagonist applied to the hindlimb enlargement (Stein and Schild, 1989). Flexion cell somata were found in all five segments of the turtle hindlimb enlargement, although the dorsal foot skin is innervated only by the D10 segment (Mortin and Stein, 1990). This finding is consistent with these cells being sensory interneurons for flexion reflex, however, because turtle primary sensory afferents can have multisegmental axons (Kunzle and Woodson, 1983), and the sensory and motor innervation for hindlimb withdrawal reflexes is multisegmental (Schouenborg, 2002; Sandrini et al., 2005). The heterogeneity of cells' morphologies and responses during flexion reflex suggests that there may be several functional types of sensory interneurons involved in flexion withdrawal reflexes. One possibility is that a subset of flexion cells projects to T neurons, which are more ventrally located and are typically activated during both fictive flexion reflex and fictive scratching (Berkowitz et al., 2006).

\section{Flexion cells are rhythmically hyperpolarized during fictive scratching and swimming}

Flexion cells were often hyperpolarized during fictive scratching and fictive swimming. Thus, these cells may contribute to mediating the depression or interruption of flexion reflex (Sherrington, 1906) and flexor reflex neural pathways (Grillner and Shik, 1973) that occurs when a rhythmic limb motor pattern is elicited. Flexion reflex can also interrupt (Sherrington, 1906, 1910) and reset (Currie and Stein, 1989; Schomburg et al., 1998) scratching and locomotor rhythms, indicating that there may be both shared circuitry and mutually inhibitory circuitry for these behaviors. Mauthner cell-mediated escape movements in fish can also interrupt and reset ongoing swim motor patterns (Svoboda and Fetcho, 1996). Knee extensor motoneurons are phasically excited and inhibited during fictive scratching, firing along with hip flexor motoneurons in fictive rostral scratching, but are in-
A

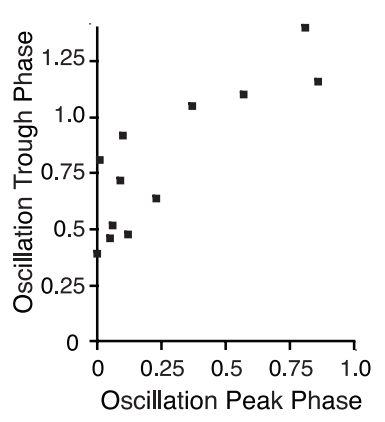

Figure 5. Quantitative analyses of flexion cell membrane potential oscillations during rhythmic motor patterns. $A$, Peak and trough phases of dual-referent phase-averaged membrane potentials of all flexion cells during ipsilateral fictive scratching. $\boldsymbol{B}$, Mean \pm SEM amplitudes of membrane potential oscillations (peak-to-trough) for all flexion cells studied during ipsilateral fictive scratching $(n=12)$ and ipsilateral fictive swimming $(n=4)$, compared with T neurons $(n=16)$ and non-T neurons $(n=14)$ during ipsilateral fictive scratching [T neuron and non- $T$ neuron data from Berkowitz et al. (2006)]. Asterisk indicates statistical significance ( $p=$ 0.0006).

hibited throughout fictive flexion reflex (Stein et al., 1982; Robertson et al., 1985; Robertson and Stein, 1988); thus, the flexion cells studied here might inhibit knee extensor motoneurons and/or excite knee flexor motoneurons.

The membrane potential of flexion cells was usually rhythmically modulated during fictive scratching and fictive swimming. Rhythmic hyperpolarization in similar interneurons might contribute to the phase dependence of flexion reflex seen in intact and spinal cats during locomotion (Forssberg et al., 1977; Forssberg, 1979). For several flexion cells, the membrane potential was most hyperpolarized during the ipsilateral hip flexor nerve bursts of fictive scratching and fictive swimming, despite the fact that all flexion cells were activated during the ipsilateral hip flexor nerve burst of fictive flexion reflex. This hip flexor phase hyperpolarization during scratching and swimming emphasizes that these cells are specialized for the limb withdrawal behavior, or the sen- 


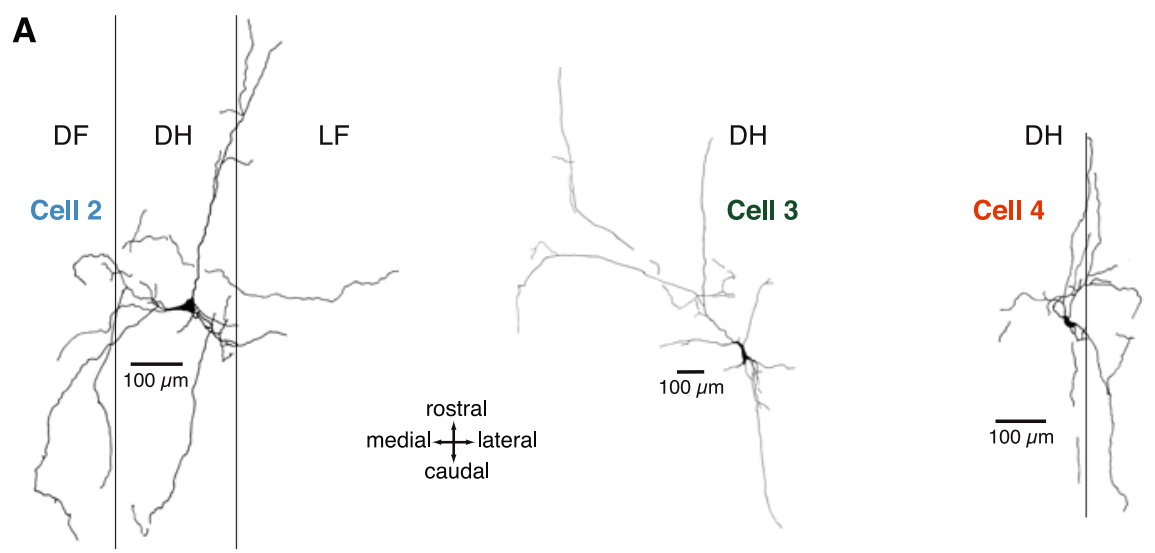

\section{Flexion cells are distinguishable from T neurons}

Flexion cells were physiologically and morphologically distinguishable from $\mathrm{T}$ neurons, which typically are activated during both fictive flexion reflex and fictive scratching and are likely to be shared elements in the generation of multiple types of hindlimb motor patterns (Berkowitz et al., 2006). All flexion cell somata were found in the dorsal horn, whereas $\mathrm{T}$ neuron somata are found mainly in the intermediate zone and ventral horn. Flexion cell dendritic trees tended to be extensive rostrocaudally but largely contained within the dorsal horn; in contrast, $\mathrm{T}$ neuron dendrites are more extensive medio-

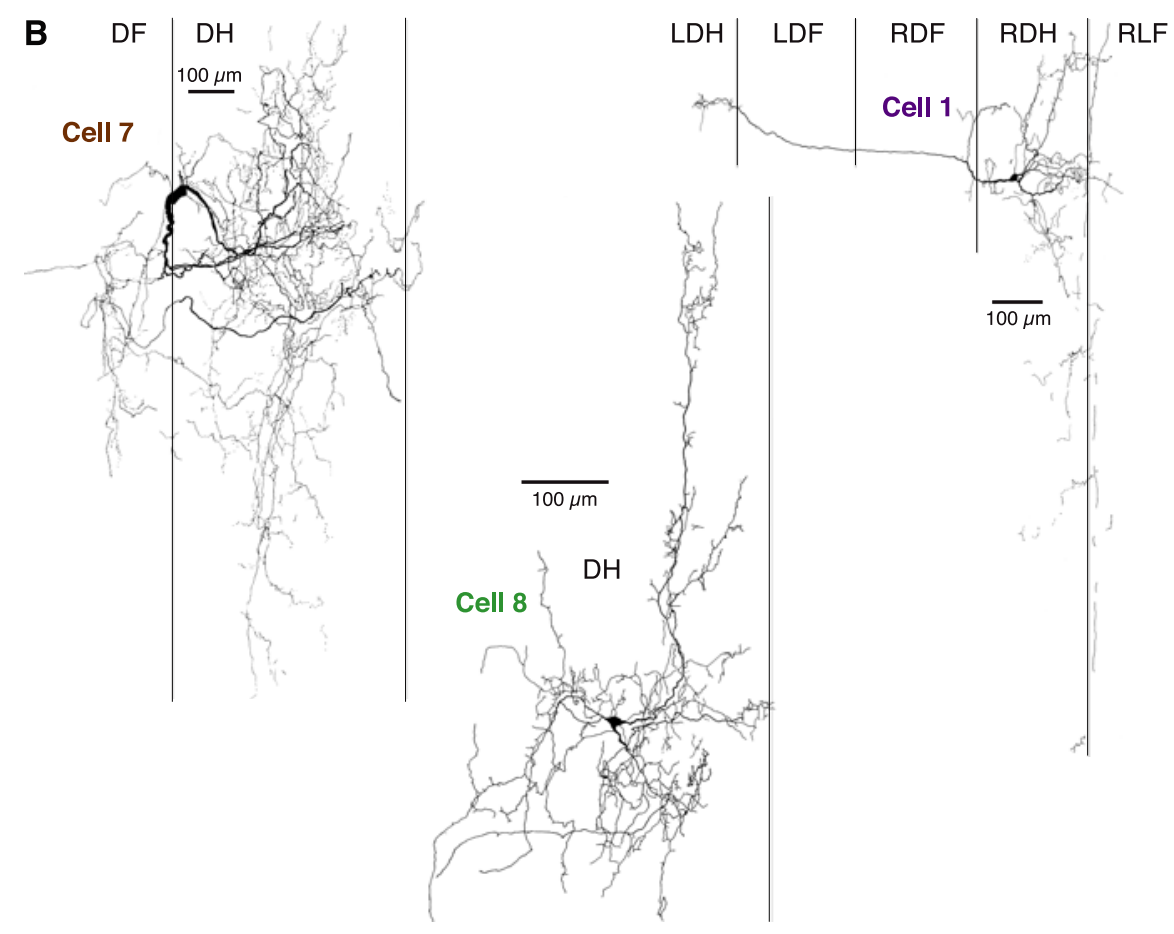

Figure 6. Morphological reconstructions of six flexion cells. $\boldsymbol{A}$, Cells with relatively simple dendritic branching. $\boldsymbol{B}$, Cells with relatively complex branching. Note that all cells have rostrocaudally extensive dendrites. DF, Dorsal funiculus; DH, dorsal horn; LF, lateral funiculus; $L$, left; $R$, right.

sory stimulus that evokes this behavior, rather than contributing generally to the hip flexor phase of a wide variety of behaviors (Jankowska et al., 1967; Lundberg, 1979; Ostry et al., 1991; Sandrini et al., 2005). Finally, there is evidence from kinematic and motor pattern analyses that limb withdrawal involves separate spinal circuitry from that used in the flexion phases of turtle scratching and frog wiping (Stein et al., 1982; Schotland and Rymer, 1993a,b).

Many flexion cells were hyperpolarized during contralateral fictive flexion reflex. These cells might mediate ipsilateral flexion reflex and receive glycinergic inhibition during contralateral flexion reflex (Currie and Stein, 1989; Currie and Lee, 1996). Some flexion cells were instead depolarized during contralateral fictive flexion reflex. These cells might contribute to the excitation of contralateral hip flexor motoneurons during ipsilateral flexion reflex that is unmasked by strychnine (Currie and Lee, 1996). laterally and dorsoventrally but less extensive rostrocaudally and arborize more in the intermediate zone, ventral horn, and white matter. $\mathrm{T}$ neuron dendritic trees are simple, with minimal higher-order branching, in contrast to a subset of flexion cells.

\section{Morphological comparisons to dorsal horn cells in other studies}

The soma locations of flexion cells were similar to those of sensory interneurons activated by $\operatorname{limb}$ skin stimulation (Schouenborg et al., 1995) and wide dynamic range neurons (Craig, 2003; You et al., 2003; Sandrini et al., 2005) in mammalian dorsal horn and overlapped with those of burst-generating neurons (Russo and Hounsgaard, 1996b), plateau-generating neurons (Russo and Hounsgaard, 1996a), and neurons showing windup (Russo and Hounsgaard, 1994) in turtle dorsal horn. Dorsolateral commissural interneurons in embryonic tadpoles also have dorsal soma locations and mediate a disynaptic reflex in which stroking the trunk skin evokes contralateral axial muscle contraction ( $\mathrm{Li}$ et al., 2003).

The rostrocaudally extensive but mediolaterally and dorsoventrally compact dendritic trees of most flexion cells seen here are similar to those of cutaneously activated local axon cells in laminas III-V of the hamster dorsal horn (Schneider, 1992), cat glutamatergic group II-activated dorsal horn interneurons (Bannatyne et al., 2006), and many cat and rodent laminas II-IV cells generally (Scheibel and Scheibel, 1969; Rethelyi et al., 1989), including cells responsive to innocuous or noxious mechanical stimuli (Light et al., 1979; Gobel et al., 1980). In addition to dendritic trees that are most extensive rostrocaudally, substantia gelatinosa neurons often have unusually complex dendritic branching and dendritic spines (Scheibel and Scheibel, 1969; Light et al., 1979; Gobel et al., 1980; Rethelyi et al., 1989; Ramon y Cajal, 1995; Grudt and Perl, 2002), similar to a subset of flexion cells found in the dorsomedial dorsal horn in this study (Fig. 6B).

The current results and other recent findings (Svoboda and Fetcho, 1996; Marder, 2000; Ritter et al., 2001; Berkowitz, 2002, 
2005) suggest that generation of several types of vertebrate hindlimb motor patterns may be mediated by a combination of shared and specialized circuitry, as has been seen in more numerous and detailed studies in invertebrates (Morton and Chiel, 1994; Marder and Calabrese, 1996; Kristan and Shaw, 1997; Edwards et al., 1999; Kupfermann and Weiss, 2001; Jing et al., 2004; Briggman et al., 2005; Marder et al., 2005; Briggman and Kristan, 2006). Moreover, the current results and a recent study in zebrafish (Ritter et al., 2001) both suggest that these shared and specialized subsets of spinal interneurons may to some extent be morphologically distinguishable.

\section{References}

Bannatyne BA, Edgley SA, Hammar I, Jankowska E, Maxwell DJ (2006) Differential projections of excitatory and inhibitory dorsal horn interneurons relaying information from group II muscle afferents in the cat spinal cord. J Neurosci 26:2871-2880.

Berkowitz A (2001) Broadly tuned spinal neurons for each form of fictive scratching in spinal turtles. J Neurophysiol 86:1017-1025.

Berkowitz A (2002) Both shared and specialized spinal circuitry for scratching and swimming in turtles. J Comp Physiol A Neuroethol Sens Neural Behav Physiol 188:225-234.

Berkowitz A (2005) Physiology and morphology indicate that individual spinal interneurons contribute to diverse limb movements. J Neurophysiol 94:4455-4470.

Berkowitz A (2006) Physiology and morphology of spinal interneurons that are preferentially activated during fictive flexion reflex. Soc Neurosci Abstr 32:448.26.

Berkowitz A, Stein PSG (1994) Activity of descending propriospinal axons in the turtle hindlimb enlargement during two forms of fictive scratching: phase analyses. J Neurosci 14:5105-5119.

Berkowitz A, Yosten GL, Ballard RM (2006) Somato-dendritic morphology predicts physiology for neurons that contribute to several kinds of limb movements. J Neurophysiol 95:2821-2831.

Briggman KL, Kristan Jr WB (2006) Imaging dedicated and multifunctional neural circuits generating distinct behaviors. J Neurosci 26:10925-10933.

Briggman KL, Abarbanel HD, Kristan Jr WB (2005) Optical imaging of neuronal populations during decision-making. Science 307:896-901.

Craig AD (2003) Pain mechanisms: labeled lines versus convergence in central processing. Annu Rev Neurosci 26:1-30.

Currie SN, Lee S (1996) Glycinergic inhibition in the turtle spinal cord regulates the intensity and pattern of fictive flexion reflex motor output. Neurosci Lett 205:75-78.

Currie SN, Stein PS (1989) Interruptions of fictive scratch motor rhythms by activation of cutaneous flexion reflex afferents in the turtle. J Neurosci 9:488-496.

Edwards DH, Heitler WJ, Krasne FB (1999) Fifty years of a command neuron: the neurobiology of escape behavior in the crayfish. Trends Neurosci 22:153-161.

Forssberg H (1979) Stumbling corrective reaction: a phase-dependent compensatory reaction during locomotion. J Neurophysiol 42:936-953.

Forssberg H, Grillner S, Rossignol S (1977) Phasic gain control of reflexes from the dorsum of the paw during spinal locomotion. Brain Res 132:121-139.

Gobel S, Falls WM, Bennett GJ, Abdelmoumene M, Hayashi H, Humphrey E (1980) An EM analysis of the synaptic connections of horseradish peroxidase-filled stalked cells and islet cells in the substantia gelatinosa of adult cat spinal cord. J Comp Neurol 194:781-807.

Grillner S, Shik ML (1973) On the descending control of the lumbosacral spinal cord from the "mesencephalic locomotor region." Acta Physiol Scand 87:320-333.
Grudt TJ, Perl ER (2002) Correlations between neuronal morphology and electrophysiological features in the rodent superficial dorsal horn. J Physiol (Lond) 540:189-207.

Jankowska E, Jukes MGM, Lund S, Lundberg A (1967) The effect of DOPA on the spinal cord. 5. Reciprocal organization of pathways transmitting excitatory action to alpha motoneurones of flexors and extensors. Acta Physiol Scand 70:369-388.

Jing J, Cropper EC, Hurwitz I, Weiss KR (2004) The construction of movement with behavior-specific and behavior-independent modules. J Neurosci 24:6315-6325.

Juranek J, Currie SN (2000) Electrically evoked fictive swimming in the lowspinal immobilized turtle. J Neurophysiol 83:146-155.

Kristan Jr WB, Shaw BK (1997) Population coding and behavioral choice. Curr Opin Neurobiol 7:826-831.

Kunzle H, Woodson W (1983) Primary afferent projections to the spinal cord and the dorsal column nuclear complex in the turtle Pseudemys. Anat Embryol (Berl) 166:229-245.

Kupfermann I, Weiss KR (2001) Motor program selection in simple model systems. Curr Opin Neurobiol 11:673-677.

Lennard PR, Stein PS (1977) Swimming movements elicited by electrical stimulation of turtle spinal cord. I. Low-spinal and intact preparations. J Neurophysiol 40:768-778.

Li WC, Soffe SR, Roberts A (2003) The spinal interneurons and properties of glutamatergic synapses in a primitive vertebrate cutaneous flexion reflex. J Neurosci 23:9068-9077.

Light AR, Trevino DL, Perl ER (1979) Morphological features of functionally defined neurons in the marginal zone and substantia gelatinosa of the spinal dorsal horn. J Comp Neurol 186:151-171.

Lundberg A (1979) Multisensory control of spinal reflex pathways. Prog Brain Res 50:11-28.

Marder E (2000) Motor pattern generation. Curr Opin Neurobiol 10:691-698.

Marder E, Calabrese RL (1996) Principles of rhythmic motor pattern generation. Physiol Rev 76:687-717.

Marder E, Bucher D, Schulz DJ, Taylor AL (2005) Invertebrate central pattern generation moves along. Curr Biol 15:R685-R699.

Mortin LI, Stein PSG (1990) Cutaneous dermatomes for the initiation of three forms of the scratch reflex in the spinal turtle. J Comp Neurol 295:515-529.

Morton DW, Chiel HJ (1994) Neural architectures for adaptive behavior. Trends Neurosci 17:413-420. 
Ostry DJ, Feldman AG, Flanagan JR (1991) Kinematics and control of frog hindlimb movements. J Neurophysiol 65:547-562.

Platt ML (2002) Neural correlates of decisions. Curr Opin Neurobiol 12:141-148.

Ramon y Cajal S (1995) Histology of the nervous system of man and vertebrates. New York: Oxford UP.

Rethelyi M, Light AR, Perl ER (1989) Synaptic ultrastructure of functionally and morphologically characterized neurons of the superficial spinal dorsal horn of cat. J Neurosci 9:1846-1863.

Ritter DA, Bhatt DH, Fetcho JR (2001) In vivo imaging of zebrafish reveals differences in the spinal networks for escape and swimming movements. J Neurosci 21:8956-8965.

Robertson GA, Stein PSG (1988) Synaptic control of hindlimb motoneurones during three forms of the fictive scratch reflex in the turtle. J Physiol (Lond) 404:101-128.

Robertson GA, Mortin LI, Keifer J, Stein PSG (1985) Three forms of the scratch reflex in the spinal turtle: central generation of motor patterns. J Neurophysiol 53:1517-1534.

Russo RE, Hounsgaard J (1994) Short-term plasticity in turtle dorsal horn neurons mediated by L-type Ca2 + channels. Neuroscience 61:191-197.

Russo RE, Hounsgaard J (1996a) Plateau-generating neurones in the dorsal horn in an in vitro preparation of the turtle spinal cord. J Physiol (Lond) 493:39-54.

Russo RE, Hounsgaard J (1996b) Burst-generating neurones in the dorsal horn in an in vitro preparation of the turtle spinal cord. J Physiol (Lond) 493:55-66.

Sandrini G, Serrao M, Rossi P, Romaniello A, Cruccu G, Willer JC (2005) The lower limb flexion reflex in humans. Prog Neurobiol 77:353-395.

Schall JD (2001) Neural basis of deciding, choosing and acting. Nat Rev Neurosci 2:33-42.

Scheibel ME, Scheibel AB (1969) A structural analysis of spinal interneurons and Renshaw cells. In: The interneuron (Brazier MAB, ed), pp 159208. Berkeley: University of California.

Schneider SP (1992) Functional properties and axon terminations of interneurons in laminae III-V of the mammalian spinal dorsal horn in vitro. J Neurophysiol 68:1746-1759.
Schomburg ED, Petersen N, Barajon I, Hultborn H (1998) Flexor reflex afferents reset the step cycle during fictive locomotion in the cat. Exp Brain Res 122:339-350.

Schotland JL, Rymer WZ (1993a) Wipe and flexion reflexes of the frog. I. Kinematics and EMG patterns. J Neurophysiol 5:1725-1735.

Schotland JL, Rymer WZ (1993b) Wipe and flexion reflexes of the frog. II. Response to perturbations. J Neurophysiol 5:1736-1748.

Schouenborg J (2002) Modular organisation and spinal somatosensory imprinting. Brain Res Rev 40:80-91.

Schouenborg J, Weng HR, Kalliomaki J, Holmberg H (1995) A survey of spinal dorsal horn neurones encoding the spatial organization of withdrawal reflexes in the rat. Exp Brain Res 106:19-27.

Sherrington CS (1906) The integrative action of the nervous system. New York: Charles Scribner's Sons.

Sherrington CS (1910) Flexion-reflex of the limb, crossed extension reflex, and reflex stepping and standing. J Physiol (London) 40:28-121.

Soffe SR (1993) Two distinct rhythmic motor patterns are driven by common premotor and motor neurons in a simple vertebrate spinal cord. J Neurosci 13:4456-4469.

Stein PSG (2005) Neuronal control of turtle hindlimb motor rhythms. J Comp Physiol A Neuroethol Sens Neural Behav Physiol 191:213-229.

Stein PSG, Schild CP (1989) N-methyl-D-aspartate antagonist applied to the spinal cord hindlimb enlargement reduces the amplitude of flexion reflex in the turtle. Brain Res 479:379-383.

Stein PSG, Robertson GA, Keifer J, Grossman ML, Berenbeim JA, Lennard PR (1982) Motor neuron synaptic potentials during fictive scratch reflex in turtle. J Comp Physiol 146:401-409.

Sugrue LP, Corrado GS, Newsome WT (2005) Choosing the greater of two goods: neural currencies for valuation and decision making. Nat Rev Neurosci 6:363-375.

Svoboda KR, Fetcho JR (1996) Interactions between the neural networks for escape and swimming in goldfish. J Neurosci 16:843-852.

You HJ, Dahl Morch C, Chen J, Arendt-Nielsen L (2003) Simultaneous recordings of wind-up of paired spinal dorsal horn nociceptive neuron and nociceptive flexion reflex in rats. Brain Res 960:235-245. 